\title{
Preventing violence in New South Wales: data sources and their adequacy
}

\author{
Alison Rutherford ${ }^{\mathrm{A}, \mathrm{B}}$ and Anthony B. Zwi ${ }^{\mathrm{A}}$ \\ ${ }^{\mathrm{A} S}$ Chool of Public Health and Community Medicine, \\ University of New South Wales \\ BCorresponding author: a.rutherford@unsw.edu.au
}

\begin{abstract}
Objectives: To describe data sources that are relevant to violence in NSW and recommend strategies for improving data collection and dissemination. Methods: Literature review, interviews with stakeholders and a survey of data custodians within NSW Health. Results: Data sources were mapped using a conceptual framework developed by the Australian Bureau of Statistics. We found that current data sources are only partially effective at characterising the burden of violence in NSW and there are inadequate mechanisms for data review and dissemination. Conclusions: Improving data collection and dissemination is the first step in the public health contribution towards reducing the burden of violence on society.
\end{abstract}

Public health efforts to prevent violence rely on information about communities most at risk of violence and the success (or otherwise) of current interventions. The World Health Organization World Report on Violence and Health recognised that information and data concerning violence are generally incomplete and inadequate for the purpose of public health action, and called for countries to enhance their ability to collect and present such data. ${ }^{1}$ In this article we describe data sources that are relevant to violence in NSW and recommend strategies for improving data collection and dissemination.

\section{Methods}

As part of a larger project we interviewed 31 key stakeholders in government and non-government organisations in the health, community, criminology, police and other sectors, and asked them about what data sources they accessed for their violence prevention work. We distributed a short survey to custodians of 11 routine data collections managed within NSW Health that we identified as being relevant to violence; of the 11 custodians, nine responded. We also searched government websites and recent published literature to identify data sources.

\section{Data sources \\ A conceptual framework}

Data sources identified were mapped using a conceptual framework that was developed by the Australian Bureau of Statistics (ABS) for mapping information relevant to sexual assault. ${ }^{2}$ This framework characterises data sources according to whether they provide information before an incident (context and risk factors), at the time of an incident (incident) or after an incident has occurred (responses and outcomes). Some datasets provide information at more than one of these levels. This information is summarised in Table 1.

\section{Examples of sources and uses of data Context}

The context in which violence occurs includes individual factors, such as prior history of aggression; relationship factors, such as peer and family norms; community factors, such as social capital and residential mobility; and societal factors, such as historical and cultural circumstances. Risk factor studies, such as census data on employment and socioeconomic status, provide information on communities at known increased risk of violence, which can be used prospectively for planning interventions. Population level information, such as population density, drug and alcohol use and the status of women and children can be studied to determine relationships between these variables and violent incidents.

Example: The 2004 National Drug Strategy Household Survey $^{3}$ found that one in three people aged 14 years and over consumed alcohol in a way that put them at increased risk of alcohol-related harm in the short-term on at least one occasion in the preceding 12 months. Risky drinking peaked in men and women aged 20-29 years.

\section{Risks}

Actual and perceived risks of violence are best documented through population surveys, including victimisation surveys, which are usually anonymous and can facilitate calculation of the prevalence of violence.

Example: The 2004 NSW Population Health Survey 4 asked young people 16-25 years of age whether or not they had been victims of physical violence in the previous 12 months. Twelve and a half percent of young people had 
Table 1. Data sources relevant to violence in NSW - conceptual framework adapted from the Australian Bureau of Statistics ${ }^{2}$

\begin{tabular}{|c|c|}
\hline Data sources & Custodian \\
\hline \multicolumn{2}{|l|}{ Context } \\
\hline National Drug Strategy Household Survey & Australian Institute of Health and Welfare \\
\hline National Illicit Drug Reporting System & National Drug and Alcohol Research Centre, UNSW \\
\hline Australian School Students Alcohol and Drugs Survey & Anti-Cancer Council of Victoria \\
\hline ABS Census & Australian Bureau of Statistics \\
\hline ABS SEIFA Indexes & Australian Bureau of Statistics \\
\hline ABS Australian Women's Year Book & Australian Bureau of Statistics \\
\hline National Firearms Monitoring Program & Australian Institute of Criminology \\
\hline Community Attitudes to Violence Against Women (2006) & Australian Institute of Criminology \\
\hline Community Atttitues about Child Abuse and Child Protection (2003) & Australian Childhood Foundation \\
\hline \multicolumn{2}{|l|}{ Other studies including policy and media analyses } \\
\hline \multicolumn{2}{|l|}{ Risk } \\
\hline Women's Safety Survey & Australian Bureau of Statistics \\
\hline National Personal Safety Survey & Australian Bureau of Statistics \\
\hline Young Australians and Domestic Violence & Australian Institute of Criminology \\
\hline Recorded Crime NSW & NSW Bureau of Crime Statistics and Research \\
\hline National Aboriginal and Torres Strait Islander Social Survey & Australian Bureau of Statistics \\
\hline National Aboriginal and Torres Strait Islander Health Survey & Australian Bureau of Statistics \\
\hline NSW Population Health Survey & NSW Health \\
\hline NSW Inmates Health Survey & Justice Health \\
\hline NSW Young People in Custody Survey & NSW Department of Juvenile Justice \\
\hline ABS Crime and Safety Survey, NSW & Australian Bureau of Statistics \\
\hline \multicolumn{2}{|l|}{ Incident } \\
\hline National Coroners' Information System & Victorian Institute of Forensic Medicine, Monash University \\
\hline Causes of Death Collection & Australian Bureau of Statistics \\
\hline National Mortality Database & Australian Institute of Health and Welfare \\
\hline National Hospital Morbidity Database & Australian Institute of Health and Welfare \\
\hline National Homicide Monitoring Program & Australian Institute of Criminology \\
\hline National Firearms Monitoring Program & Australian Institute of Criminology \\
\hline Recorded Crime NSW & NSW Bureau of Crime Statistics and Research \\
\hline NSW Criminal Court Statistics & NSW Bureau of Crime Statistics and Research \\
\hline NSW Inpatient Statistics Collection & NSW Health \\
\hline NSW Emergency Department Data Collection & NSW Health \\
\hline NSW Physical Abuse and Neglect of Children Data Collection & NSW Health \\
\hline DOCS Client Information System (KIDS) & NSW Department of Community Services \\
\hline $\begin{array}{l}\text { BEACH (Bettering the Evaluation and Care of Health) dataset } \\
\text { Centre }\end{array}$ & Australian General Practice Statistics and Classification \\
\hline NSW Child Death Review Team Reports & NSW Commission for Children and Young People \\
\hline Prison Injury Surveillance System & Justice Health \\
\hline \multicolumn{2}{|l|}{ Individual clinic/medical records in public and private services } \\
\hline \multicolumn{2}{|l|}{ Responses } \\
\hline NSW Sexual Assault Data Collection & NSW Health \\
\hline NSW Physical Abuse and Neglect of Children Data Collection & NSW Health \\
\hline NSW Domestic Violence Screening Snapshot & NSW Health \\
\hline NSW Health Incident Information Management System & NSW Health \\
\hline NSW Criminal Court Statistics & NSW Bureau of Crime Statistics and Research \\
\hline NSW Mental Health Outcomes Assessment Tool & NSW Health \\
\hline NSW Sentinel Events Review Committee Reports & NSW Health \\
\hline Alcohol and other Drug Treatment Services National Minimum Data Set & Australian Institute of Health and Welfare \\
\hline Juvenile Justice National Minimum Data Set & Australian Institute of Health and Welfare \\
\hline Child Protection National Minimum Data Set & Australian Institute of Health and Welfare \\
\hline Admitted Patient Care National Minimum Data Set & Australian Institute of Health and Welfare \\
\hline Community Mental Health Care National Minimum Data Set & Australian Institute of Health and Welfare \\
\hline Admitted Patient Mental Health Care National Minimum Data Set & Australian Institute of Health and Welfare \\
\hline Trauma Incident Review Teams & NSW Institute of Trauma and Injury Management \\
\hline \multicolumn{2}{|l|}{ Impacts and outcomes } \\
\hline Cost of Domestic Violence to the Australian Economy & Access Economics \\
\hline International Violence Against Women Survey & Australian Institute of Criminology \\
\hline Women's Health Australia & University of Newcastle \\
\hline Injury Costs! & NSW Injury Risk Management Research Centre \\
\hline Other studies assessing outcomes of violence & \\
\hline
\end{tabular}


experienced a violent incident. The young men who had been physically assaulted were most likely to be assaulted in an outdoor place or a licenced premise, whereas young women who had experienced physical assault were more likely to be assaulted in the home.

\section{Incident}

Information at the incident level is primarily provided by routine datasets such as the NSW Inpatient Statistics Collection, NSW Recorded Crime Statistics ${ }^{5}$ and the ABS Mortality Collection. NSW Ambulance Service data could potentially provide information about violent incidents but are currently insufficiently sensitive for this purpose. The national Bettering the Evaluation and Care of Health $(\mathrm{BEACH})$ general practice dataset includes information about violence coded according to International Classification of Primary Care (ICPC) codes, but the number of identified incidents of violence is very small.

Example: The NSW Inpatient Statistics Collection demonstrates that approximately 6000 people are admitted to hospitals in NSW every year for 'interpersonal violence' and males are three to four times more likely to be admitted than females. ${ }^{6}$

\section{Responses}

Data describing responses to violence by the health system include the National Minimum Data Sets collected through health service delivery points, such as drug and alcohol services, ${ }^{4}$ mental health services, trauma centres and child protection services and incident monitoring systems, such as the NSW Health Incident Information Management System, which documents reported violent incidents affecting clients or staff within NSW health services. In addition, specific mechanisms have been established in part to analyse system responses to serious incidents, such as the NSW Child Death Review Team ${ }^{7}$ and the Mental Health Sentinel Event Review Committee. ${ }^{8}$

Example: National data on patient-safety-related incidents from national incident management data demonstrated that from January 1998 to June 2002, 3621 incidents within the health system involved physical violence or a violent verbal exchange. ${ }^{9}$ The proportion of total incidents involving violence was higher in emergency departments and much higher in mental health units. These data were used to recommend strategies to train and protect staff in methods to deal with violent incidents.

\section{Impacts and outcomes}

The impacts and outcomes of violence are poorly described in current data collections. In particular, there is generally poor assessment of the psychological impacts of violence. Economic studies of the impacts of violence are important but have been conducted infrequently. ${ }^{10,11}$
Example: The NSW Injury Risk Management Research Centre estimated the costs to NSW of various forms of injury during the period 1998-99. ${ }^{12}$ The study estimated that self- harm was the second most costly form of injury to NSW (\$588 million) and assaults were the fifth most costly mechanism of injury (\$134 million). Falls are the most costly mechanism of injury at an estimated $\$ 644$ million in 1998-99.

\section{NSW Health data sources relevant to violence}

Table 2 provides an overview of the strengths and limitations of specific datasets relevant to violence managed by NSW Health, based on the comments of our informants, results of the survey conducted and a review by the UNSW team.

\section{Adequacy of current datasets}

Stakeholders interviewed were asked in general terms about the adequacy of the data sources they use. Some common themes emerged from these discussions:

\section{Data sources are not comparable}

Different data sources measure different variables, making comparison difficult. For example, sexual violence may be measured through data on presentations to sexual assault centres, presentations to emergency departments, police reports, court reports and population surveys measuring histories of sexual violence in childhood or adulthood. Sexual violence is defined differently in each of these data collections: for example, the legal definition of sexual assault used in criminal prosecution is much narrower than the definitions of sexual victimisation used in population surveys. Given that these collections are not linked, it is difficult to know how much overlap there is. One stakeholder from outside the health sector articulated the need for different sectors to share data more effectively:

'The links between assault prevention, health outcomes and violence prevention are so clear, it is almost ridiculous that we are not sitting at a table on a monthly basis and comparing data...if anything can be done better it is the way we compare data'.

\section{Significant under-reporting}

In concert with literature in the area, stakeholders interviewed perceived there to be significant under-reporting of intimate partner violence, sexual violence, elder abuse, school bullying and assaults on hospital staff. Some stakeholders were reluctant to identify violence if they perceived it would compromise provision of care or that there were inadequate referral mechanisms to follow up events identified: 'We are not seeking to get individual level reporting of stuff around DV (domestic violence), child reporting... we wouldn't know what to do with it'. Underidentification of Indigenous status and inaccurate reporting of violence in Indigenous communities were also reported. 


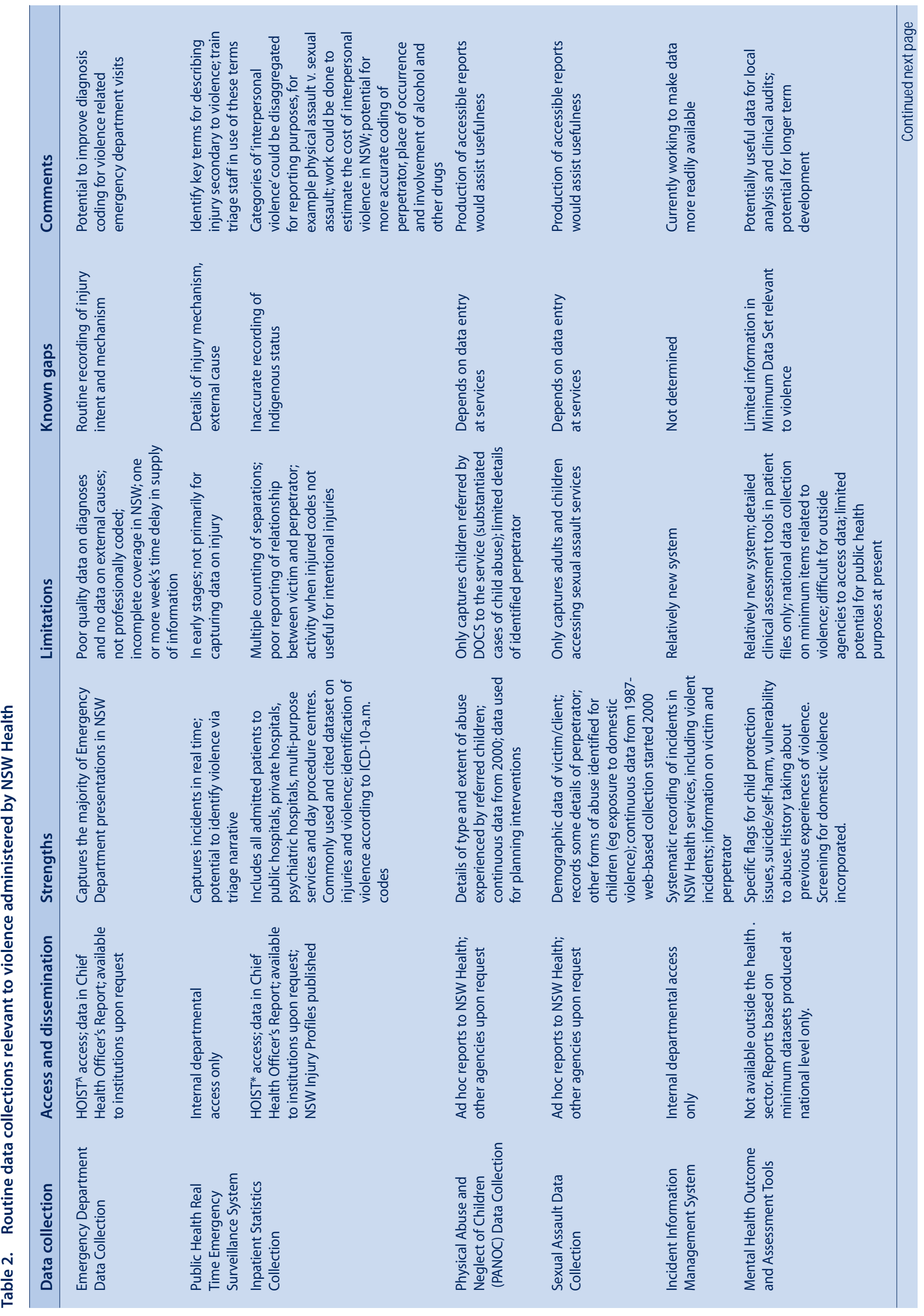




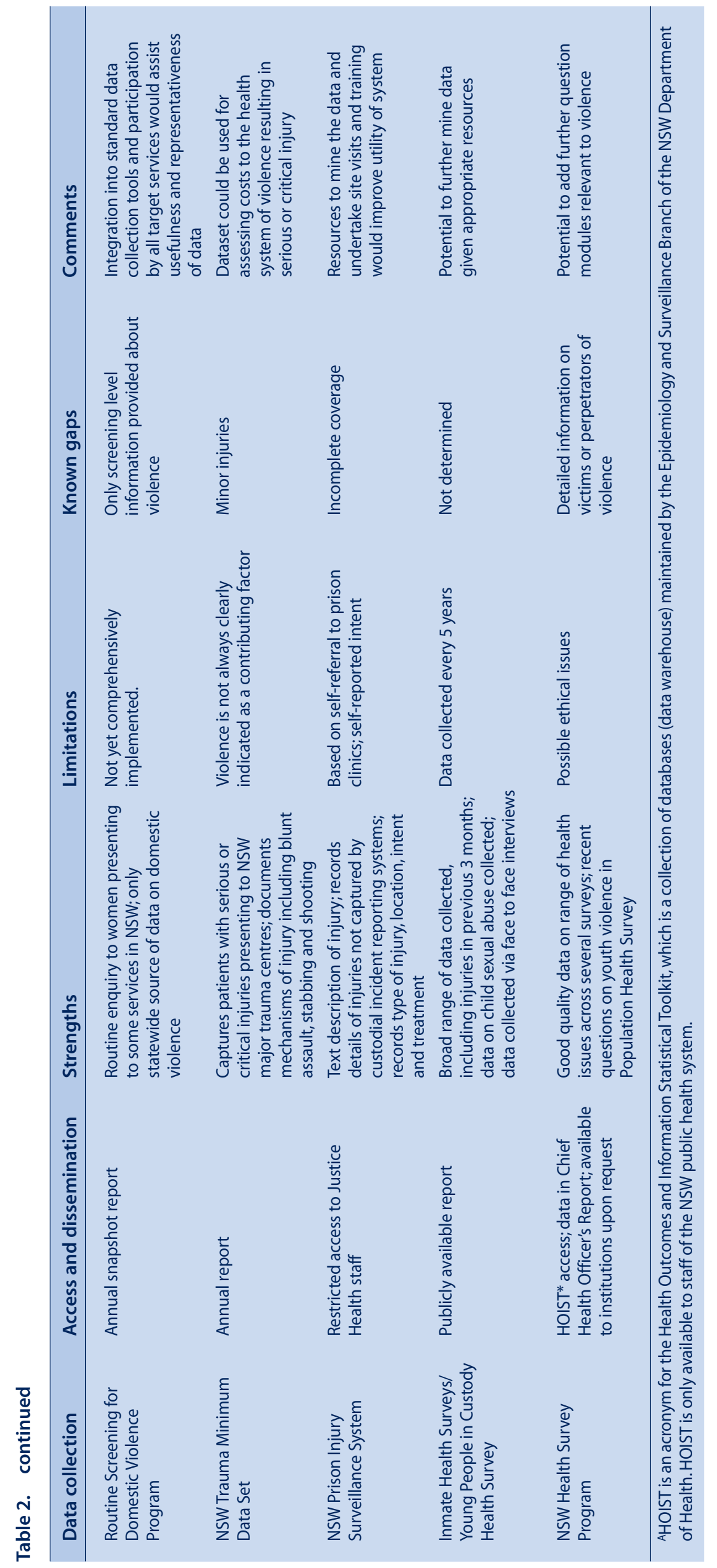


Inadequate identification of intent, external causes of violence and the relationship between victim and perpetrator

The majority of victims of violence seen in the health sector are not admitted to hospital, but are seen in the emergency department or as outpatients. However, most data collections beyond the Inpatient Statistics Collection do not routinely record the intent of injuries, the external cause of injuries and the relationship between the victim and perpetrator. Although the Emergency Department Data Collection was identified as a key information source for improvement, this collection does not function primarily as

Table 3. Key resources relevant to violence prevention in NSW

Organisation/document title
Australian Childhood Foundation
Aboriginal Child Sexual Assault Taskforce
AlHW National Injury Surveillance Unit
Australian Institute of Health and Welfare
Allerton M, Kenny D, Champion U, Butler T. NSW young people
in custody health survey: A summary of key findings.
Sydney: NSW Department of Juvenile Justice, 2003.
Australian Bureau of Statistics

Australian Centre for the Study of Sexual Assault

Australian Domestic and Family Violence Clearinghouse

Australian Institute of Criminology

BEACH (Bettering the Evaluation and Care of Health)

Bureau of Crime Statistics and Research, NSW AttorneyGeneral's Department

Al-Yaman F, Van Doeland M, Wallis M. Family violence among Aboriginal and Torres Strait Islander peoples. Canberra: AlHW November 2006.

Illicit Drug Reporting System, National Drug and Alcohol Research Centre

Justice Health, Inmate Health Survey 2001

National Association for the Prevention of Childhood Abuse and Neglect

National Child Protection Clearinghouse

National Coroners Information System

NSW Chief Health Officer's Report 2004

health/chorep/chorep.html

NSW Child Deaths Review Team

NSW Health Inpatient Statistics Collection

NSW Health Routine Screening for Domestic Violence

Snapshot Report 2004

NSW Health Survey 2004

NSW Injury Risk Management Research Centre

NSW Institute of Trauma and Injury Management

Memmott P, Stacy R, Chambers C, Keys C. Violence in indigenous communities. Canberra: Commonwealth Attorney-General's Department, 2001

Mouzos J, Makkai T. Women's experiences of male violence: findings from the Australian component of the International Violence Against Women Survey (IVAWS). Canberra: Australian Institute of Criminology, 2004

Office for the Status of Women \& Access Economics, The Costs of Domestic Violence to the Australian Economy, 2004

Women's Health Australia (The Australian Longitudinal Study on Women's Health)
URL

\section{www.childhood.org.au}

http://www.lawlink.nsw.gov.au/acsat

http://www.nisu.flinders.edu.au

http://www.aihw.org.au

www.aic.gov.au/conferences/2003-juvenile/kenny.html

http://www.abs.gov.au/websitedbs/d3310114.nsf/ Home/themes- go to Crime and Justice and Health themes. http://www.aifs.gov.au/acssa/index.html

http://www.austdvclearinghouse.unsw.edu.au/

http://www.aic.gov.au/

http://www.fmrc.org.au/beach.htm

http://www.lawlink.nsw.gov.au/lawlink/bocsar/

II_bocsar.nsf/pages/bocsar_aboutus

http://www.aihw.gov.au/publications/index.cfm/title/10372

http://notes.med.unsw.edu.au/NDARCWeb.nsf/page/IDRSa

http://www.justicehealth.nsw.gov.au/pubs/Inmate_

Health_Survey_2001.pdf

www.napcan.org.au

http://www.aifs.gov.au/nch/

http://www.vifp.monash.edu.au/ncis

http://www.health.nsw.gov.au/public-

http://www.kids.nsw.gov.au/publications/cdrt2000.html http://www.health.nsw.gov.au/im/ims/isc/

http://www.health.nsw.gov.au/pubs/2005/routine_ screeningfn.html

http://www.health.nsw.gov.au/public-health/survey/hs04/ prodout/toc/toc.htm

http://www.irmrc.unsw.edu.au/

http://www.itim.nsw.gov.au

http://www.ncp.gov.au/agd/www/Ncphome.nsf/Page/ 3AF90A4576B81394CA256B430001AF24?OpenDocument

http://www.aic.gov.au/publications/rpp/56/index.html

www.accesseconomics.com.au

http://www.alswh.org.au/ 
a surveillance system and significant barriers to collecting good quality data in this setting were identified.

\section{Accessing health data is difficult unless you know how}

Several stakeholders outside the health sector reported that health data were difficult to access unless you knew where to look: 'Health is such a complicated organisation from the outside'. One suggested that it would be 'really good to have a contact in Health we can call up and say - right is it realistic for us to ask for this information - does it exist?' Another thought that 'A one-stop shop outlining the health data, who is the data custodian, how you get access to it...something like that would be beneficial'.

\section{Some data are misleading}

There are some communities 'hidden' in the statistics, such as gay and lesbian victims of both intimate partner and street violence, as most datasets do not record information on sexual identity. One stakeholder felt very strongly that the health sector collects poor quality data on child health, including child abuse, as most information is collected via parents rather than from children themselves.

\section{Discussion}

Public health surveillance should enable the definition of public health priorities; the characterisation of disease by time, place and person; the detection of unusual patterns of occurrence or epidemics; the evaluation of prevention and control programs; and the projection of future trends and health care needs. ${ }^{13}$ All of these are relevant to violence, which can be detected to some degree in routine datasets at the incident level. However, certain forms of violence are likely to be significantly under-reported, ${ }^{14,15}$ and even large scale victimisation surveys have been unable to systematically document the experiences of some groups, such as adult survivors of sexual assault, people from non-English speaking backgrounds, sex workers and the homeless. ${ }^{2}$

All routine data collection systems have weaknesses; added to these are some specific limitations of data collected about violence. Particular issues are the lack of resources and personnel to focus on violence in particular, and the use of non-standardised terms and protocols which limit the comparability of results derived from separate data sources or data collection instruments. ${ }^{16}$

To facilitate a broad understanding of the complex patterns of violence within society, information from different sources and different sectors is required. The increased use of data linkage methods is likely to assist with making these data more useful. Table 3 summarises the range of information that is available to violence prevention practitioners in NSW. It is not sufficient to characterise violence using only the ICD codes for assault in the NSW Inpatient Statistics Collection. Basing policy on these measures of morbidity alone will significantly underestimate the burden of violence in NSW. As victims of violence have higher health care needs and consume more health resources than those who have not been victimised, ${ }^{1,17}$ it is appropriate that health systems pay particular attention to identifying violence and target programs to where they are most needed.

Collecting information about personal experiences of violence highlights specific ethical and logistic issues that may not be relevant to other forms of information gathering. In particular, respondents should not be adversely affected or revictimised in any way by participating in data collection. ${ }^{2}$ Routine datasets often collect data on violence as a by-product of their main purpose, and are therefore unlikely to compromise staff time or patient acceptability. However, as discussed previously, many victims of violence are unlikely to be identified unless more active methods of information gathering are instituted.

\section{Conclusions}

Current information systems to characterise violence in NSW are only partially effective. Stakeholders reported that data about violence in general were not representative, were of variable quality and were difficult to access. In addition, there appear to be few systematic mechanisms by which information about violence is regularly reviewed and fed back into policy processes. Key recommendations arising from this project are currently being formulated for consideration by NSW Health.

Public health research, advocacy and intervention depend upon accurate estimations of the burden of injury. Improving information systems is the first step in the public health contribution to reducing the burden of violence on society.

\section{Acknowledgements}

This work was funded by the Injury Prevention and Policy Branch, NSW Health. We would like to thank Pam Albany and Caroline Finch for their support. We would also like to thank all the stakeholders who took part in the interviews and surveys.

\section{References}

1. Krug EG, Dahlberg LL, Mercy JA, Zwi AB, Lozano R, editors. World report on violence and health. Geneva: World Health Organization, 2002.

2. Australian Bureau of Statistics. Information paper: sexual assault information development framework 4518.0. Canberra: Australian Bureau of Statistics, 2003.

3. Australian Institute of Health and Welfare. 2004 national drug strategy household survey. In: Drug statistics series No 16. Canberra: Australian Institute of Health and Welfare, 2005.

4. Centre for Epidemiology and Research NSW Department of Health. 2004 Report on Adult Health. N S W Public Health Bull 2005; 16(S-1). 
5. Moffatt S, Goh D, Fitzgerald J. NSW recorded crime statistics 2004. Sydney: NSW Bureau of Crime Statistics and Research, 2005.

6. Hayen A, Mitchell R. A description of interpersonal violencerelated hospitalisations in New South Wales, 1989-00 to 2003-04. N S W Public Health Bull 2006; 17: 8-12.

7. NSW Child Death Review Team. Fatal assault and neglect of children and young people. Sydney: NSW Commission for Children and Young People, 2003.

8. NMHSER Committee. Tracking Tragedy 2004: A systemic look at homicide by mental health patients and suicide deaths of patients recently discharged from mental health inpatient units. 2005, NSW Health: Sydney.

9. Benveniste K, Hibbert P, Runciman W. Violence in health care: the contribution of the Australian Patient Safety Foundation to incident monitoring and analysis. Med J Aust 2005; 183(7): $348-51$.

10. Access Economics. The cost of domestic violence to the Australian economy. Canberra: Office of the Status of Women, Australian Government, 2004

11. VicHealth. The health costs of violence: measuring the burden of intimate partner violence. Melbourne: Victorian Health Promotion Foundation, 2004.
12. Potter-Forbes M, Aisbett C. Injury costs! A valuation of the burden of injury in NSW 1998-1999. Sydney: NSW Injury Risk Management Research Centre, 2003.

13. Berkelman R, Stroup D, Buehler J. Public health surveillance. In: Detels R, Mcewen J, Beaglehole R, Tanaka H, editors. The Oxford textbook of public health. Oxford: Oxford University Press, 2002.

14. Carcach C. Reporting crime to the police. In: Trends and issues in crime and criminal justice. Canberra: Australian Institute of Criminology, 1997.

15. Mouzos J, Makkai T. Women's experiences of male violencefindings from the Australian component of the International Violence Against Women Survey. Canberra: Australian Institute of Criminology, 2004.

16. Watts C, Zimmerman C. Violence against women: global scope and magnitude. Lancet 2002; 359: 1232-7.

17. Plichta S. Intimate partner violence and physical health consequences: policy and practice implications. $J$ Interpers Violence 2004; 19(11): 1296-323. doi:10.1177/ 0886260504269685 